University of South Florida

DIGITAL COMMONS

Digital Commons @ University of

@ UNIVERSITY OF SOUTH FLORIDA

South Florida

QMaSC: A Handbook for Directors of

Quantitative and Mathematics Support Centers

USF Libraries

$1-1-2016$

\title{
14. Training Materials and Methods
}

Johnathan Nelson

University of St. Thomas

Follow this and additional works at: https://digitalcommons.usf.edu/qmasc_handbook

\section{Recommended Citation}

Johnathan Nelson (2016), "Training Materials and Methods", http://dx.doi.org/10.5038/

9780977674435.ch14 in G. Coulombe, M. O'Neill, M. Schuckers (Eds.) A Handbook for Directors of Quantitative and Mathematical Support Centers, Neck Quill Press, http://scholarcommons.usf.edu/ qmasc_handbook.

This Staffing, Hiring, and Training is brought to you for free and open access by the USF Libraries at Digital Commons @ University of South Florida. It has been accepted for inclusion in QMaSC: A Handbook for Directors of Quantitative and Mathematics Support Centers by an authorized administrator of Digital Commons @ University of South Florida. For more information, please contact digitalcommons@usf.edu. 


\section{Training Materials and Methods}

(c) Johnathan Nelson,

University of St. Thomas

प्र

\section{Introduction}

This chapter opens with a discussion of tutoring practices and methods that a director of a QMaSC center would be wise to go over with his or her tutors; it continues with a discussion of different ways that a director could conduct training sessions, and closes with a look at different approaches that different directors take towards training tutors in content knowledge.

\section{Training Tutors in Tutoring Practices and Methods: What Should be Covered}

It does not take an expert to tell you that knowledge is not sufficient for being a good tutor; one needs to know how to communicate with the individual being tutored in a way that will allow him or her to retain the knowledge, and use it on his or her own. QMaSC directors should and do recognize this when setting up their tutor training programs. According to a survey of 22 QMaSC directors at schools across the country[1], the majority of tutor training that QMaSC's conduct covers tutoring methods and practices, i.e., strategies and techniques used when helping students. There is a good deal of consensus among the directors surveyed regarding what methods and practices are the best.

Suggested Citation: Johnathan Nelson (2016), "Training Materials and Methods", http://dx.doi.org/10. 5038/9780977674435.ch14 in G. Coulombe, M. O'Neill, M. Schuckers (Eds.) A Handbook for Directors of Quantitative and Mathematical Support Centers, Neck Quill Press, http://scholarcommons.usf.edu/qmasc_handbook

This material is based upon work supported, in part, by the National Science Foundation under Grant DUE1255945. Any opinions, findings, and conclusions or recommendations expressed in this material are those of the author(s) and do not necessarily reflect the views of the National Science Foundation 


\section{Relational Understanding}

Perhaps the single most important principle for tutors to know is that their role is to help students achieve real understanding of the material, as opposed to merely helping students find the right answers. Richard Skemp, author of the 1976 math education classic "Relational Understanding and Instrumental Understanding," says that tutors should help students achieve relational understanding, by which he means "knowing both what to do and why," instead of mere instrumental understanding, which he describes as "rules without reasons." [2] Although QMaSC directors may not use these terms, much of the training that they conduct has the aim of making tutors see the importance of helping students achieve relational understanding.

Patrice Conrath of Bethel University instills this principle in her tutors by telling them that she sees the main job of their center as "working itself out of a job," i.e., helping students to truly understand the material and adopt an approach towards mathematics that will allow them to be better learners in the future. She encourages her tutors to use a "hands behind your back" strategy, in which tutors do as little "showing" as possible. "If we plow through problems," she says "and show them the 'way to do it,' they may think some steps are magic, they might not understand some of the terms, and they may have thought about [how to do a problem] in a completely different, but correct way." She encourages her tutors to build off of the student's own ideas, as this will make it easier for students to integrate new knowledge into their existing framework of understanding.

Rosalie Tepper of Shoreline Community College conveys this same principle to her tutors by telling them that it is not the tutor's role to do the work for the students, but rather to "think of [their role] as asking leading questions and giving hints." This helps students draw on their prior knowledge, which allows them to make connections leading to deeper understanding. Tepper finds that other benefits come from this approach as well: "It keeps them awake and paying attention Also, having the student do as much as possible helps me (when working with a student) gauge their understanding, which in turn allows me to tailor my methods to them." By using questions, she finds it easier to identify the specific part of the problem that she needs to focus on with the student, and what parts of the problem the student already understands. She sees little pedagogical value in just showing students what to do. "Even if (after just showing students what to do) we ask the student 'do you understand what I did?' they might say 'yes' even if it's not true, due to embarrassment at their lack of comprehension, a belief that the tutor can't explain it better, or just a lack of interest," she says. Tepper says that it occasionally happens that a student's prior knowledge will be inadequate to build from, and in these cases the best thing for the tutor to do may involve more "showing" than would normally be recommended. In these instances, she says, it is a good idea to "make up a related example with different numbers, so that the student still has to do his or her homework problem."

Many other QMaSC directors share practices and methods with their tutors that will lead to 
relational understanding. Marcia Frobish of Grand Valley State University finds it important to train her tutors in questioning skills; she tries to have the tutors help students by "asking them, rather than telling them." Cat McCune of Smith College also tells her tutors to ask questions, not to "teach/tell," and to "keep the pencil in the hand of the tutee." Tiana Bosley of Wayne State University takes a similar approach, saying, "It is important for the tutor to "not hold the pencil.' He or she needs to ask leading questions to get the tutee involved in thinking and solving the problem. It also helps the tutor assess how much the tutee may know." Maria Belk of Bard College tells her tutors to provide hints and, when these fail, to work through problems similar to the one the student is asking about, rather than simply giving the answer or doing the problem for the student. Thomas Dick of Oregon State University encourages his tutors to have the students "think aloud" about their approach to problems.

\section{Interpersonal Skills and Professionalism}

Many QMaSC directors also find it important to train their tutors in interpersonal skills, i.e., forming a friendly-but-professional relationship with the students they help. According to the survey, tutors should be trained in maintaining patience when students get frustrated or belligerent, developing a relationship with the tutee that makes them feel that its safe to ask questions, and in being generally upbeat and positive; in the words of Cat McCune of Smith College, tutors should be "aggressively enthusiastic" when greeting new students.

One common situation that tests tutors' professionalism is when students complain about their professors. It is important that tutors not join in, which would turn the tutoring session into a "professor bashing" session. Patrice Conrath of Bethel University tells her tutors to listen to the comments, but not join in. It is okay to acknowledge the students frustration, she tells them, but then to move on. She encourages her tutors to say things like "I'm sorry you are frustrated, I know it is hard, but let's attack the material." She wants her tutors to have positive attitudes, showing students "the excitement of doing math and the perseverance to plow through when it's tough."

\section{FERPA and Confidentiality}

Tutors should definitely be made aware of the Family Education Rights and Privacy Act (FERPA) [3] , which pertains to them as employees of the educational institution. FERPA prohibits school employees from divulging information to anyone other than the student about that student's academic records (including appointments for tutoring sessions or sign-ins to the QMaSC) other than for strictly professional reasons [2]. In general, the best policy would be that tutoring sessions are

confidential and, while tutors can discuss experiences with a student for the purpose of improving the help that they give him or her, they need to be careful that they are not gossiping, or talking about particular students that they tutor, with friends who are not tutors. 


\section{Other Training Topics to Consider}

QMaSC directors mention many other methods and practices that they cover in tutor training, including being aware of what course students are in so that course-appropriate approaches to each problem can be provided, how to work with more than one student at a time, what tutors should do when they get stuck, how to work with students from different cultures or who are English

language learners, how to use answer keys properly, how to work with different learning styles, how to avoid being monopolized by especially needy students, strategies for addressing math anxiety, and making sure that help is authorized for the assignment that the student is asking about. Every QMaSC director should consider the approach that they want their tutors to take in dealing with these issues, but each director's preferred approach will likely vary, as differences in the way the QMaSC is set up, institutional or departmental curriculum, testing policies, demographics, and student support and disability services will need to be taken into consideration.

\section{Training Tutors in Tutoring Practices and Methods: How to Conduct Training Sessions}

Most of the QMaSC directors surveyed conduct training on tutoring practices and methods in an employee orientation session. The directors reported that their sessions lasted between 1 and 6 hours. In addition to covering basic employee information (expectations, how to find a sub, recording hours, etc.) these sessions also can include mock tutoring sessions, where tutors take turns acting as a student or as a tutor and offer one another feedback on how they did, or a scripted, staged session in which tutors (or the director) act out the "dos and don'ts" of tutoring. Many directors also have handouts that they give their tutors for reading and discussion; these handouts can include materials that the director has prepared covering tutoring practices and methods, as well as articles on teaching and learning that can be read and discussed.

Most QMaSC directors also have ongoing training for tutors. A common approach is to have meetings at the beginning of each semester; other directors conduct training more frequently. Most directors require tutors to attend training sessions (especially new tutors), but are generally pretty flexible when tutors have conflicts. Some conduct make-up sessions for tutors who were unable to make the original meeting; others put training materials online or send meeting notes to tutors who were unable to attend.

Rosalie Tepper of Shoreline Community College says that she sees the interview process as the beginning of training. During interviews with prospective tutors, she explains her tutoring philosophy (described in the previous section) with students, and lets them try to put it into action in a mock-tutoring session. She also has ongoing training to reinforce the practices and methods that she recommends to her tutors. 
At the University of St. Thomas, "Effective Math Tutoring Tips," written by George Dennis of Lower Columbia College, is used to introduce new tutors to effective practices and methods [4]. Dennis provides a number of tips useful in helping tutors adopt an approach that will encourage students to truly learn the material and become better independent learners. All of the tutors, new and returning, read and discuss Dennis' tips in the beginning-of-the-school-year meeting; this is especially effective because veteran tutors point out which of the tips they find particularly useful, which validates the tips in the minds of the new tutors. Skemp's "Relational Understanding and Instrumental Understanding" is also shared with the tutors, many of whom have likely seen the value of relational understanding in their own studies, but reading this article can solidify its importance in their minds.

Patrice Conrath of Bethel University says she likes to include time for tutor discussion led by her veteran tutors during training sessions. Conrath has a great strategy for making these discussions as fruitful as possible:

To solicit some of these lead tutor ideas, I will often put up a Google doc about a week before our monthly lab training meetings, and ask the lead tutors to write about current issues in the labs. They interact on this Google doc, brainstorming together, and then I divide up and organize issues and have different tutors lead different discussions at the meeting (usually the ones they brought up, or had good ideas about). I will lead the meeting, but they do most of the talking. It really goes quite well, and other tutors actively engage in the discussions and will feel empowered to contribute as well in this format. I have often wished I had brought a camera to record these fruitful discussions and may do so in the future.

Conrath says that her veteran tutors often have seen for themselves the value of the practices and methods that she advocates, and it can be good for the newer tutors to hear their peers reinforce her ideas. Also, being students themselves, the tutors can provide insight into professor expectations and student culture that will help their peers.

There is also information that a director may find helpful to use in conducting training sessions put out by the College Reading and Learning Association (CRLA) and by the National Tutoring Association. The CRLA guide provides a comprehensive guide to general tutor training topics and also a section specific to mathematics [4]; the National Tutoring Association has a code of ethics and information, as well as information on certification, workshops, and conferences [5].

\section{Training Tutors in Mathematical and Quantitative Content}

Some QMaSC directors cover mathematical or quantitative content in their training sessions, but many do not. Many QMaSC directors say that, since the tutors that they hire have taken 
several math classes, have earned good grades in these classes, and have strong recommendations from faculty members, they assume that the tutors will have no problems with the content. Others say that they would perhaps like to train tutors in content, but it is unrealistic to do so because there would be too much material to cover. Centers that focus more tutoring for quantitative courses may find it difficult to cover the wide range of disciplines and courses that they support.

Furthermore, the set-up of each QMaSC can affect the need for content training. For example, Bethel University's QMaSC has large numbers of tutors working at the same time (although it is open for fewer hours than many other institutions' QMaSCs), so even if some of the tutors cannot provide help on a given topic, there is usually at least one tutor who can.

QMaSC directors that do think it important to train tutors in mathematical content believe that tutors especially benefit from training in topics from basic math or pre-calculus and trigonometry, application-type questions from various courses, and topics from mid-level mathematics courses. Tiana Bosley of Wayne State University says that she finds it important to train tutors in content from lower level math courses, as often a good deal of time has passed since the tutors studied some of this content themselves. Darry Andrews of Ohio State University finds that tutors often are "rusty" in explaining how to set up word problems, and so would benefit greatly from training that would cover applications. Dennis Lewandowski of Michigan Technological University notes that his tutors do not always feel comfortable with topics from Calculus 3, Differential Equations, or Linear Algebra; his content training is driven by their suggestions, and is conducted in his meetings with what he calls "open discussion," i.e., having the tutors that are confident with the material share their knowledge with those that are not.

At the University of St. Thomas, tutor training on mathematical content is held, and it is very beneficial. Although the tutors that work in the St. Thomas' QMaSC have earned high grades in their classes, and have strong recommendations from math faculty, their knowledge of many topics could use some shoring up. Many students that come into our QMaSC seeking help are in Finite Mathematics, an applications-based lower level math course. Topics from this course include probability and financial math, which the tutors often do not study until their senior year, if at all. Also, there are concepts in college algebra and trigonometry (such as the rational zero test for polynomials and trigonometric identities, to name a couple) that undergraduate students do not often use after initially learning them (which many tutors did in high school). Finally, there are difficult topics from Calculus II and Multivariable Calculus, such as sequences and series or vector calculus, that even strong students can struggle to understand, and so it is beneficial for the tutors to spend some time reviewing these topics as well.

During the 2012-2013 school year, a new approach to tutor training on mathematical content was tried at St. Thomas; topics, in which many tutors were relatively weak, were chosen and associated worksheets designed and distributed to help the tutors review these topics. Referencing course schedules provided by professors, training sessions for each topic were scheduled on a date 
when professors were beginning to cover that topic in their courses. During the training sessions, the tutors worked through the material, discussing with one another and getting help when needed. Attendance at the training sessions was optional, tutors who couldn't make training could pick up the worksheet for study on their own. However, tutors were given brief tests on each topic covered in training, and each tutor was expected to pass at least 5 tests throughout the year (a total of 14 tests were given; tutors could pick and choose which tests to prepare for and take). It was pleasing to see that many of the tutors chose to be tested on topics in which they knew that they had previously struggled, and that most tutors had no trouble in passing the minimum number of tests, and some tutors even took well more than the minimum number (the tutors could record hours spent at training sessions or taking the tutor tests, and also were promised an extra raise to tutors who passed at least 10 tests throughout the year). However, it was somewhat disappointing to find that some tutors did not feel like they could put in the time to prepare for the tests; the expectation that tutors pass at least 5 tests ended up being one enforced with some "flexibility." Overall, though, this program seemed to be helpful in making the tutors better able to help students.

\section{Conclusions}

There is much variety in how QMaSC directors conduct tutor training, and in what they cover. Much of this variation arises naturally from differences between institutions.

It seems, however, that many of the methods and practices advocated by QMaSC directors are oriented towards helping students achieve what Skemp would call "relational understanding," as opposed to "instrumental understanding." Also, QMaSC directors find it important to train tutors in how to interact with students, professional behavior, FERPA, and many other areas, several of which will require institution-specific approaches. Most directors accomplish this training through a combination of orientation sessions for new tutors and ongoing training sessions for continuing tutors, and find mock tutoring sessions, handouts outlining important strategies, and tutor-led discussions to be effective ways of conveying best methods and practices to the tutors.

When setting up a tutor training program, a QMaSC director should also consider whether or not training should be conducted on mathematical content. Factors to be considered include how well the tutors' knowledge will line up with the topics that they will be asked about and the amount of time that can reasonably be spent on training the tutors in mathematical content. The extent of content training can vary greatly, from ad hoc tutor-led discussions of the needed review material to systematic content training with worksheets and tests.

\section{Bibliography}

[1] J. Nelson, "QMaSC Director Survey Re: Training." survey, 2013. 
[2] R. Skemp, "Relational understanding and instrumental understanding," Mathematics Teaching in the Middle School, vol. 12, pp. 88-95, September 2006. Reprinted from Mathematics Teaching, December 1976.

[3] U.S. Department of Education, Family Policy Compliance Office, "Family Educational Rights and Privacy Act (FERPA)." http://www.ed.gov/policy/gen/guid/fpco/ferpa/ index.html, 2013.

[4] G. Dennis, "Tutor training handbook." http://www.webpages.uidaho.edu/bestpractices/ peer_train_math.html, 2013.

[5] K. Agee and R. Hodges, Handbook for Training Peer Tutors and Mentors. Independence, KY: Cengage, 2012.

\section{Acknowledgements}

Thank you to the numerous directors of QMaSCs throughout the country who participated in my survey, especially those who shared more of their thoughts in follow-up emails.

Thank you to all of the participants in this project, whose feedback has been of immense value in bringing this section to its final edition, especially Mary O'Neill, who was specifically charged with editing this section.

Thank you also to the Mathematics Department of the University of St. Thomas for supporting my participation in this project. 